\title{
Intra-abdominal localized hyaline-vascular Castleman disease: imaging characteristics and management of a rare condition
}

Nikolaos Vassos ${ }^{1}$, Dimitrios Raptis ${ }^{1}$, Michael Lell ${ }^{2}$, Peter Klein ${ }^{1}$, Aristotelis Perrakis ${ }^{1}$, Jens Köhler ${ }^{3}$, Roland S. Croner ${ }^{1}$, Werner Hohenberger ${ }^{1}$, Abbas Agaimy ${ }^{4}$

\author{
'Department of Surgery, University Hospital Erlangen, Erlangen, Germany \\ ${ }^{2}$ Institute of Diagnostic and Interventional Radiology, University Hospital Erlangen, \\ Erlangen, Germany \\ ${ }^{3}$ Department of Surgery, Nuremberg Medical Center, Nuremberg, Germany \\ ${ }^{4}$ Institute of Pathology, University Hospital Erlangen, Erlangen, Germany
}

Submitted: 26 March 2014

Accepted: 25 June 2014

Arch Med Sci 2016; 12, 1: 227-232

DOI: $10.5114 /$ aoms.2016.57600

Copyright @ 2016 Termedia \& Banach

Castleman disease (CD) is a rare lymphoproliferative disorder of unknown etiology and one of the uncommon causes of nonneoplastic lymphadenopathy. Earlier synonyms of CD included angiofollicular lymph node hyperplasia, giant lymph node hyperplasia, lymphoid hamartoma, benign lymphoma and follicular lymphoreticuloma. This disease was first reported by Castleman et al. in 1954 [1] and later defined by Castleman et al. in 1956 in a series of 13 patients with unicentric hyaline vascular CD presenting with large thymoma-like masses in the anterior mediastinum [2]. The condition was later found to be occasionally associated with hypochromic anemia, hypergammaglobulinemia and bone marrow plasmacytosis [3, 4]. By the late 1960s and the early 1970s, the histological features of the different forms of the disease and the classification in current use had been established $[5,6]$. The disease features three main histopathological presentations: hyaline vascular, plasma cell-rich, and mixed variants $[6,7]$. The exact incidence of CD is unknown. Association of certain forms of the disease with the human immunodeficiency virus (HIV) and human herpes virus-8 (HHV-8) infections has been long recognized. In 1985, Lachant et al. reported on 2 patients with the acquired immunodeficiency syndrome (AIDS) who developed multicentric CD followed by Kaposi sarcoma [8]. In 1995, Soulier et al. reported frequent coincidence of HHV-8 in 31 patients with multicentric CD [9].

Castleman disease may develop at any age and involve any nodal or extranodal site without gender predilection $[6,10,11]$. The clinical manifestations are heterogeneous, ranging from asymptomatic lymphadenopathy to recurrent episodes of generalized lymphadenopathy with severe constitutional symptoms. Clinically, CD may present with unicentric (unifocal or localized) or multicentric (multifocal or generalized) disease [10]. The first case of multicentric CD was reported in 1978 [11], followed by recognition of the salient differences between hyaline vascular and plasma cell variants and their association with unicentric and multicentric presentation [12,13]. Clinical diagnosis is difficult and often confirmed only after histological evaluation of surgical specimens. Herein, we report 4 cases of abdominal hyaline vascular CD, illustrating their clinical, radio-

\author{
Corresponding author: \\ Nikolaos Vassos MD \\ Department of Surgery \\ University Hospital Erlangen \\ Krankenhausstrasse 12 \\ D-91054 Erlangen, Germany \\ Phone: +49-9131-85-33296 \\ Fax: +49-9131-85-36294 \\ E-mail: nikolaos.vassos@ \\ uk-erlangen.de
}


logic and pathologic features, and discuss them in the light of a review of the literature.

Case 1: A 19-year-old man was admitted because of right upper abdominal pain for 1 year. He had no history of constitutional symptoms and he denied any alcohol or drug abuse. He had a history of chronic microcytic hypochromic anemia and was not a HIV patient. Abdominal examination, gastroscopy and colonoscopy revealed no abnormal findings. Magnetic resonance imaging (MRI) showed a sharply circumscribed, $4 \mathrm{~cm}$ solid mass between the transverse colon and proximal jejunum (Figure 1). Radiological differential diagnosis was mesenchymal neoplasm or vascular tumor. An explorative laparotomy was indicated because of constant abdominal pain. At surgery, the tumor was found to be located near the mesenteric root, but well circumscribed without infiltrating adjacent organs. A surgical excision with clear margins was performed. Grossly, the tumor was round, well circumscribed and encapsulated. The cut surface was brown-purple and had a rubbery, granular appearance. Histopathological examination revealed hyperplastic lymphoid tissue characterized by numerous evenly distributed small follicles, most of which contained atrophic hyalinized germinal centers (Figures $2 \mathrm{~A}-\mathrm{B}$ ). Thin vessels traversed the mantle zone and entered radially the hyalinized germinal centers (Figures $2 \mathrm{C}$ ). The mantle zone showed an onion skin-like pattern. Extensive interstitial sclerosis was seen in the central part of the tumor in this case (Figure $2 \mathrm{D}$ ). Immunohistochemistry and molecular analysis for B- and T-cell receptor rearrangements showed polyclonal results. No HHV-8 positive cells were detected. These findings were consistent with the diagnosis of "hyaline vascular" CD. The patient is currently (2 years later) without recurrence.

Case 2: An otherwise healthy 22-year-old woman was found to have a mass in the right upper quadrant of the abdomen detected incidentally upon diagnostic workup for newly diagnosed acute hepatitis $C$. Physical examination revealed no pathological findings. Laboratory blood analysis including tumor markers (CA 19-9 and carcinoembryonic antigen) was normal, except for positive HCV RNA and positive antibodies to HCV. Serological testing for HIV was negative. Ultrasound examination (US) showed a hypoechoic solid mass with a distinct vascular pattern on color
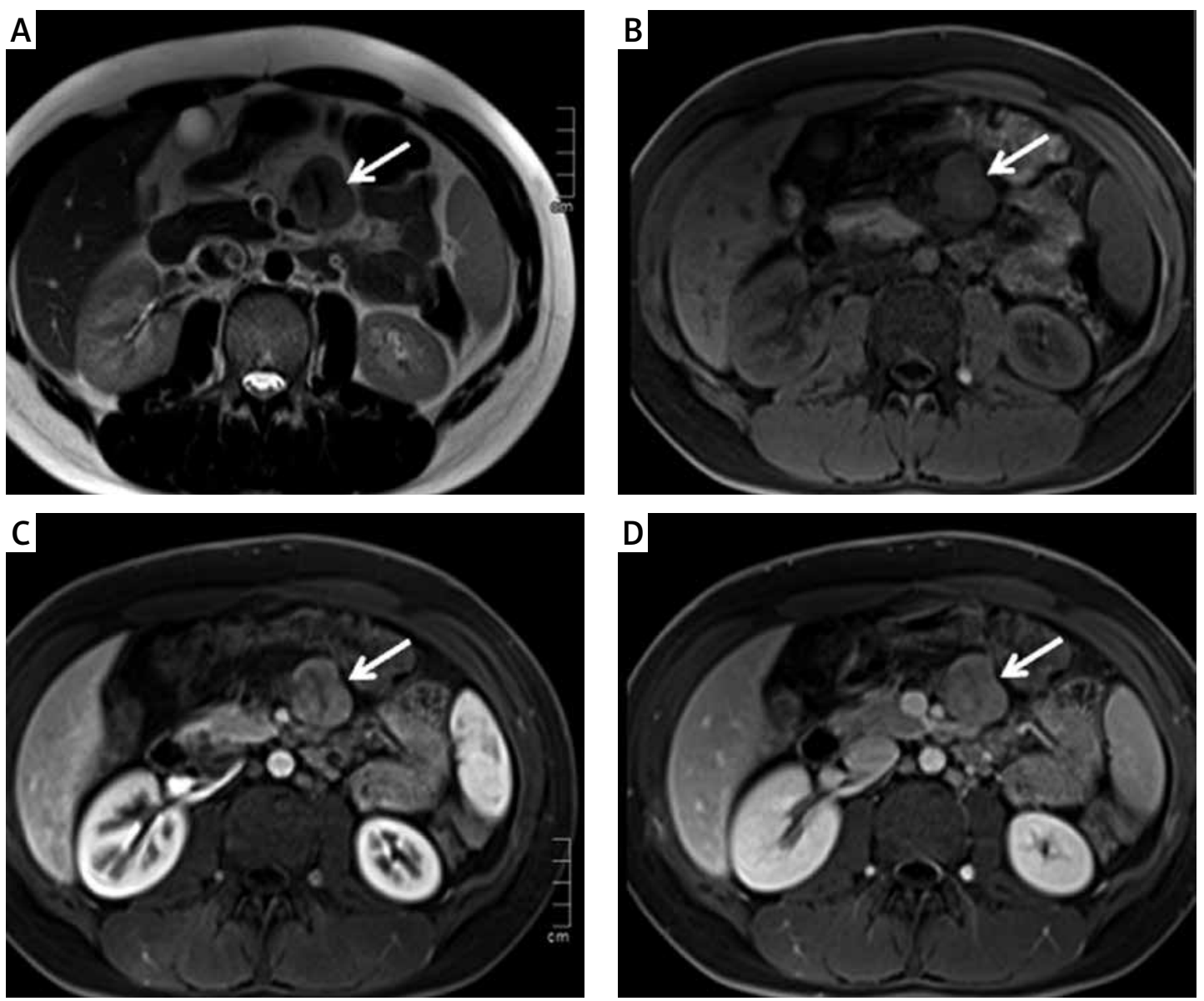

Figure 1. Transverse section of the abdomen (T2 - HASTE (A), T1 - VIBE before contrast material injection (B), during arterial (C) and venous phase (D) demonstrating well-circumscribed, slightly inhomogeneous, moderately enhancing $3.5 \times 2.5 \times 5.5 \mathrm{~cm}$ mass (arrow) in the mesentery root) 

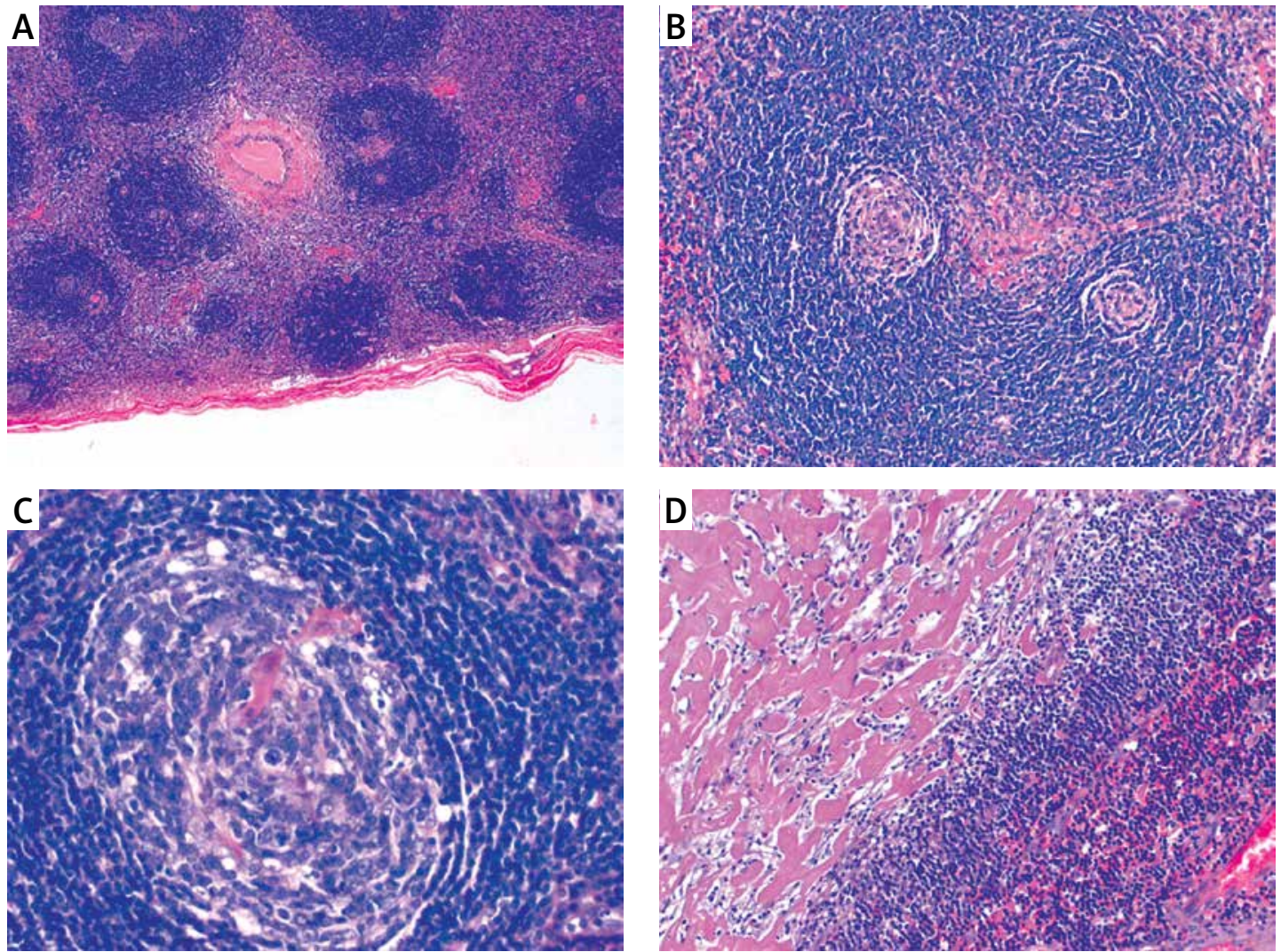

Figure 2. Histopathological features of hyaline-vascular localized Castleman disease. A - At low power, encapsulated mass with numerous large lymphoid follicles showing prominent mantle zone but small atrophic germinal centers. B - Many follicles contained more than one germinal center. C - Onion skin mantle zone. In this field a hyperplastic germinal center is seen traversed by a hyalinized vessel. D - Case 2 showed prominent confluent sclerosis consistent with a heterogeneous appearance on imaging

Doppler US. Contrast-enhanced abdominal computed tomography (CT) confirmed a $5 \mathrm{~cm}$, well-defined, round, solid hypervascular mass under the caudate lobe of the liver with intense contrast enhancement. Magnetic resonance imaging confirmed the findings and excluded further hepatic lesions. Possible differential diagnoses on imaging were lymphoma, mesenchymal neoplasm or vascular tumor. At laparotomy, the mass was located under the liver and was supplied by a branch of the gastroduodenal artery. The mass was removed with free margins. Currently the patient is free of disease 11 years after surgery. The histopathological findings were identical to case one.

Case 3: A 55-year-old woman with a history of breast cancer and negative serological testing for HIV was diagnosed with an abdominal mass on US examination due to upper abdominal pain. A CT scan revealed a $6 \times 3 \times 3 \mathrm{~cm}$, well-defined, round, solid hypervascular mass between the pancreas and the proximal jejunum, mimicking a vascular tumor. Because of intestinal obstruction a laparotomy was indicated; at laparotomy, the mass was located near the mesenteric root, infiltrating the first loop of the jejunum. Complete surgical excision of the mass with segmental re- section of the jejunum was performed (Figure $3 \mathrm{~A}$ ). The histopathological findings were consistent with "hyaline vascular" CD as detailed above. Currently, the patient is well and free of disease 10 years after surgery.

Case 4: A 31-year-old man was found to have a mesenteric tumor of unknown origin in the right upper quadrant of the abdomen detected accidentally during a preventive medical examination. He was in a good general status without any abdominal or systemic symptoms. Serological testing was negative for viral hepatitis and HIV. The findings of an ultrasound-guided fine needle biopsy were not conclusive. At surgery, the tumor was found to be located near the mesenteric root, encasing the superior mesenteric artery. Surgical excision was performed without clear margins because of the risk of small bowel under-perfusion (Figure $3 \mathrm{~B}$ ). The histopathological findings were identical to the above cases. Three years later, during follow-up care, CT showed a well-circumscribed, solid mesenteric mass $10 \mathrm{~cm}$ in size. Under suspicion of recurrent disease, an explorative laparotomy was performed and the tumor was surgically removed with a segmental resection of jejunum. Histopathological examination revealed mesenteric desmoid 

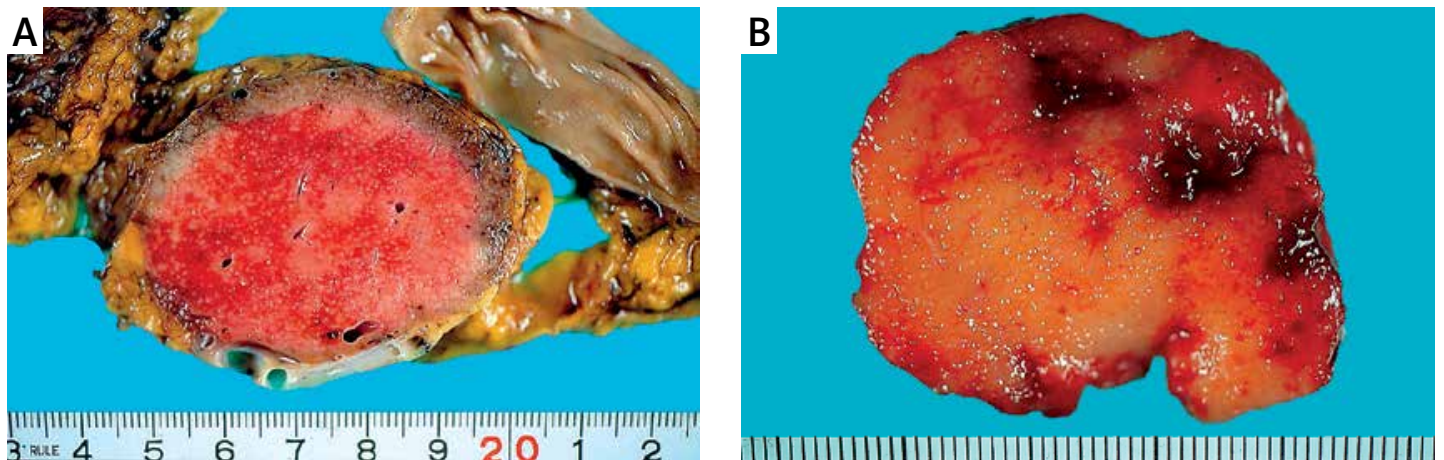

Figure 3. Gross features of hyaline vascular intra-abdominal Castleman disease. A - Large, well-circumscribed mass with brown homogeneous cut surface and prominent granulation indicating lymphoid aggregates (image from case 3). This intra-mesenteric lesion could be removed completely together with a small bowel segment. Note prominent grossly recognizable vessels. B - Another mesenteric CD mass (case 4) showed fragile tan-yellow and hyperemic granular cut surface. This lesion could not be removed completely due to encasement of mesenteric vessels

fibromatosis but no evidence of recurrent CD. Currently, the patient is well, without recurrence of $C D$ or desmoid tumor (7 years after initial surgery).

Castleman disease most frequently affects the mediastinum (65\%), neck (16\%), abdomen (12\%), and axilla $(3 \%)[14,15]$. The mesentery, retroperitoneum and abdominal lymph nodes are the most commonly involved abdominal organs [6]. Affected extra-nodal sites include lungs, larynx, parotid gland, meninges and soft tissue [6,16].

The etiology and pathophysiological basis of CD are still unclear [17]. Dysregulation or dysplasia of follicular dendritic cells and inflammatory mediators (interleukin-6 - IL-6) have been incriminated, mainly in the multicentric form of the disease [18]. Increased serum IL-6 level is positively correlated with active disease [19], and removal of the CD mass may result in an abrupt drop in IL-6 levels and resolution of symptoms [20]. Furthermore, treatment with IL-6 antagonists relieves symptoms and signs of the disease [21]. Chronic low-grade inflammation and immunodeficiency including autoimmune diseases are considered to be possible causal factors of $C D$ [22]. Furthermore, viral infections (HHV-8, EBV) $[23,24]$ and others have been reported in association with CD [16]. None of our patients had evidence of any chronic inflammatory or autoimmune disorder.

The unicentric or localized type of CD involves a single lymph node or localized lymph node station. It represents the most common form of the disease (> 90\%) and is almost always asymptomatic and of hyaline-vascular type. The size of lesions varies greatly $(1-12 \mathrm{~cm})$ [25]. In contrast, multicentric CD occurs in about $10 \%$ of patients [26] and is almost always symptomatic but with highly varying symptoms which may progress over several months or episodically over years [12]. A large proportion of patients experience fever, night sweats, weakness, fatigue, anorexia, weight loss and other constitutional symptoms. Virtually all patients have multifocal lymphadenopathy, and more than half have features of hepatosplenomegaly [25]. A range of laboratory abnormalities including anemia, thrombocytopenia, elevated erythrocyte sedimentation rate, abnormal liver function and polyclonal hyperglobulinemia are observed in patients with multicentric CD [26]. Multicentric CD commonly results in a fatal outcome due to infectious complications, multi-organ failure and occasional development of malignancies $[25,27]$. Neoplastic complications include Kaposi sarcoma and lymphoma (Hodgkin's and non-Hodgkin) as well as plasma cell dyscrasias [9, 27].

The diagnosis of $C D$ is based on clinical evaluation, which includes patient history, laboratory studies and imaging. The utility of US, CT, MRI and positron emission tomography (PET) scanning has been assessed in CD [28-32], but a final diagnosis can be achieved only histologically [16]. On US, CD often presents as a well-demarcated hypoechoic mass with a homogeneous pattern. The classic appearance of CD on CT scan is that of a homogeneous mass of soft tissue density which is intensely enhanced following contrast administration and may rarely be accompanied by calcification [31, 33]. Heterogeneity is usually a reflection of intralesional sclerosis, necrosis and degeneration in larger lesions [32, 33]. On MRI, the lesions are typically heterogeneous with an increased signal as compared to skeletal muscles on T1-weighted images and marked hyperintensity on T2-weighted images [34]. CD is usually positive on fluorodeoxyglucose (FDG) PET [35].

The differential diagnosis of intra-abdominal CD includes lymphoma, sarcoma, lymph node metastasis, gastrointestinal stromal tumor, paraganglioma and infectious/inflammatory diseases (abscess, tuberculosis, chronic pancreatitis) [29]. Multicentric CD may also closely mimic IgG4-related disease [36]. Elevated IL-6 levels (in favor of CD) and serum lgG4 abnormalities (suggesting IgG4-related lymphadenopathy) may help in the differential diagnostic workup [37]. 
The treatment of choice for CD is based on clinical and pathological subtype. Surgery, radiotherapy, steroids, immunotherapy and combination chemotherapy have all been used in varying combinations in different settings to manage the disease [16, 26, 30, 38-41]. Complete surgical excision remains the most often used treatment for unicentric $C D$ regardless of histological type, which is curative in almost all cases [15, 42]. The recurrence rate is low, even after subtotal resection, and it can be cured by re-excision [10, 43, 44]. In our non-HIV patients with localized CD, complete (3 cases) and subtotal (1 case) surgical resection permitted histological diagnosis and at the same time resulted in patients' cure. As diagnosis is usually rendered on resection specimens, postoperative imaging and laboratory investigations should be performed for appropriate classification of the disease. Rare cases of hyaline-vascular CD from abdominal and other peripheral extra-nodal sites have been complicated by follicular dendritic cell sarcoma $[45,46]$.

Unlike patients with localized $C D$, there is no consensus on the optimal management strategy for multicentric $C D[10,25,26]$. Surgical removal of involved lymph nodes and/or masses results in only transient improvement of systemic symptoms, probably due to a "debulking" effect [47]. Successful treatment of symptomatic multicentric CD has been achieved using different chemotherapeutic agents [32, 47-49]. Radiation therapy may represent an alternative for symptomatic relief for patients with surgical contraindications or in those with infeasible complete surgical excision or as a palliative option in multicentric $C D[10,11,39,49,50]$.

In conclusion, $C D$ is a rare lymphoproliferative disorder of uncertain etiology with a wide spectrum of clinicopathological presentation. Assessment of disease extent (unicentric versus multicentric) and presence or absence of symptoms and/or associated or underlying diseases (autoimmune disorders, HIV, etc.) largely determine the modality and extent of treatment on an individual basis.

\section{Acknowledgments}

Nikolaos Vassos and Dimitrios Raptis equally contributed.

\section{Conflict of interest}

The authors declare no conflict of interest.

\section{References}

1. Castleman B, Towne VW. Case records of the Massachusetts General Hospital; weekly clinicopathological exercises; founded by Richard C. Cabot. N Engl J Med 1954; 251: 396-400.
2. Castleman B, Iverson L, Menendez VP. Localized mediastinal lymphnode hyperplasia resembling thymoma. Cancer 1956; 9: 822-30.

3. Lee SL, Rosner F, Rivero I, et al. Refractory anemia with abnormal iron metabolism: its remission after resection of hyperplastic mediastinal lymph nodes. N Engl J Med 1965; 272: 761-6.

4. Tung KS, McCormack LJ. Angiomatous lymphoid hamartoma. Report of five cases with a review of the literature. Cancer 1967; 20: 525-36.

5. Flendrig JA, Schiillings PHM. Benign giant lymphoma: the clinical signs and symptoms and the morphological aspects. Folia Med 1969; 12: 119-20.

6. Keller AR, Hochholzer L, Castleman B. Hyaline-vascular and plasma-cell types of giant lymph node hyperplasia of the mediastinum and other locations. Cancer 1972; 29: 670-83.

7. Casper C. The aetiology and management of Castleman disease at 50 years: translating pathophysiology to patient care. Br J Haematol 2005; 129: 3-17.

8. Lachant NA, Sun NC, Leong LA, et al. Multicentric angiofollicular lymph node hyperplasia (Castleman's disease) followed by Kaposi's sarcoma in two homosexual males with the acquired immunodeficiency syndrome (AIDS). Am J Clin Pathol 1985; 83: 27-33.

9. Soulier J, Grollet L, Oksenhendler E, et al. Molecular analysis of clonality in Castleman's disease. Blood 1995; 86: 1131-8.

10. Bowne WB, Lewis JJ, Filippa DA, et al. The management of unicentric and multicentric Castleman's disease: a report of 16 cases and a review of the literature. Cancer 1999; 85: 706-17.

11. Gaba AR, Stein RS, Sweet DL, et al. Multicentric giant lymph node hyperplasia. Am J Clin Pathol 1978; 69: 86-90.

12. Frizzera G, Banks PM, Massarelli G, et al. A systemic lymphoproliferative disorder with morphologic features of Castleman's disease. Pathological findings in $15 \mathrm{pa}-$ tients. Am J Surg Pathol 1983; 7: 211-31.

13. Weisenburger DD, Nathwani BN, Winberg CD, et al. Multicentric angiofollicular lymph node hyperplasia: a clinicopathologic study of 16 cases. Hum Pathol 1985; 16: 162-72.

14. Wei BP, Taylor R, Chan YF, et al. Mesenteric Castleman's disease in childhood. ANZ J Surg 2004; 74: 502-4.

15. Bucher P, Chassot G, Zufferey G, et al. Surgical management of abdominal and retroperitoneal Castleman's disease. World J Surg Oncol 2005; 3: 33.

16. van Rhee F, Stone K, Szmania S, et al. Castleman disease in the 21st century: an update on diagnosis, assessment and therapy. Clin Adv Hematol Oncol 2010; 8: 486-98.

17. Rieu P, Noel LH, Droz D, et al. Glomerular involvement in lymphoproliferative disorders with hyperproduction of cytokines (Castleman, POEMS). Adv Nephrol Necker Hosp 2000; 30: 305-31.

18. Ruco LP, Gearing AJ, Pigott R, et al. Expression of ICAM-1, VCAM-1 and ELAM-1 in angiofollicular lymph node hyperplasia (Castleman's disease): evidence for dysplasia of follicular dendritic reticulum cells. Histopathology 1991; 19: 523-8.

19. Parravicini C, Corbellino M, Paulli M, et al. Expresion of alpha virus-derived cytokine, KSHV vIL-6, in HIV-seronegative Castleman's disease. Am J Pathol 1997; 151: 1517-22.

20. Yoshizaki K, Matsuda T, Nishimoto N, et al. Pathogenic significance of interleukin-6 (IL-6/BSF-2) in Castleman's disease. Blood 1989; 74: 1360-7. 
21. Nishimoto N, Kanakura Y, Aozasa K, et al. Humanized anti-interleukin-6 receptor antibody treatment of multicentric Castleman disease. Blood 2005; 106: 2627-32.

22. Muskardin TW, Peterson BA, Molitor JA. Castleman disease and associated autoimmune disease. Curr Opin Rheumatol 2012; 24: 76-83.

23. Yamasaki $S$, lino $T$, Nakamura $M$, et al. Detection of human herpesvirus-8 in peripheral blood mononuclear cells from adult Japanese patients with multicentric Castleman disease. Br J Haematol 2003; 120: 471-7.

24. Suda T, Katano H, Delsol G, et al. HHV-8 infection status of AIDS-unrelated and AIDS-associated multicentric Castleman's disease. Pathol Int 2001; 51: 671-9.

25. Herrada J, Cabanillas F, Rice L, et al. The clinical behavior of localized and multicentric Castleman disease. Ann Intern Med 1998; 128: 657-62.

26. Waterston A, Bower M. Fifty years of multicentric Castleman's disease. Acta Oncol 2004; 43: 698-704.

27. Oksenhendler E, Boulanger E, Galicier L, et al. High incidence of Kaposi sarcoma-associated herpesvirus-related non-Hodgkin lymphoma in patients with HIV infection and multicentric Castleman disease. Blood 2002; 99: 2331-6.

28. Sanna G, Barone D, Midiri M, et al. Ultrasonographic features with color Dopler, with computerized tomography and angiography in a case of abdominal Castleman's disease. Radiol Med 1997; 93: 804-5.

29. Oida Y, Shimizu K, Mukai M, et al. FDG-PET and diffusion weighted MR imaging appearance in retroperitoneal Castleman's disase: a case report. Clin Imaging 2008; 32: 144-6.

30. Madan R, Chen JH, Trotman-Dickenson B, et al. The spectrum of Castleman's disease: mimics, radiologic pathologic correlation and role of imaging in patient management. Eur J Radiol 2012; 81: 123-31.

31. Talat N, Schulte KM. Castleman's disease: systematic analysis of 416 patients from the literature. Oncologist 2011; 16: 1316-24.

32. Ko SF, Hsieh MJ, Ng SH, et al. Imaging spectrum of Castleman's disease. AJR Am J Roentgenol 2004; 182: 769-75.

33. Meador TL, McLarney JK. CT features of Castleman disease of the abdomen and pelvis. AJR Am J Roentgenol 2000; 175: 115-8.

34. Kim TJ, Han JK, Kim YH, et al. Castleman disease of the abdomen: imaging spectrum and clinicopathologic correlations. J Comput Assist Tomogr 2001; 25: 207-14.

35. Chander S, Westphal SM, Zak IT, et al. Retroperitoneal malignant peripheral nerve sheath tumor: evaluation with serial FDG-PET. Clin Nucl Med 2004; 29: 415-8.

36. Sato Y, Kojima M, Takata K, et al. Systemic IgG4-related lymphadenopathy: a clinical and pathologic comparison to multicentric Castleman's disease. Mod Pathol 2009; 22: 589-99.

37. Cheuk W, Chan JK. IgG4-related sclerosing disease: a critical appraisal of an evolving clinicopathologic entity. Adv Anat Pathol 2010; 17: 303-32.

38. Kumari P, Schechter GP, Saini N, et al. Successful treatment of human immunodeficiency virus-related Castleman's disease with interferon-alpha. Clin Infect Dis 2000; 31: 602-4.

39. Chronowski GM, Ha CS, Wilder RB, et al. Treatment of unicentric and multicentric Castleman disease and the role of radiotherapy. Cancer 2001; 92: 670-6.

40. Marcelin AG, Aaron L, Mateus C, et al. Rituximab therapy for HIV-associated Castleman disease. Blood 2003; 102: 2786-88.
41. Nishimoto N, Sasai M, Shima Y, et al. Improvement in Castleman's disease by humanized anti-interleukin- 6 receptor antibody therapy. Blood 2000; 95: 56-61.

42. Chen CH, Liu HC, Tung KY, et al. Surgical outcome of superficial and deep Castleman disease. ANZ J Surg 2007; 77: 339-43.

43. Ushio T, Yoshimura K, Kojima A, et al. A case of Castleman's disease that recurred nine years after initial surgical removal. Nippon Kyobu Shikkan Gakkai Zasshi 1994; 32: 1175-80.

44. Kim MH, Hwang S, Choi YB, et al. Castleman disease of the abdomen-single-center experience of 13 surgically treated patients over 11 years. Hepatogastroenterology 2010; 57: 1060-3.

45. Hwang SO, Lee TH, Bae SH, et al. Transformation of Castleman's disease into follicular dendritic cell sarcoma, presenting as an asymptomatic intra-abdominal mass. Korean J Gastroenterol 2013; 62: 131-4.

46. Kazakov DV, Morrisson C, Plaza JA, et al. Sarcoma arising in hyaline-vascular Castleman disease of skin and subcutis. Am J Dermatopathol 2005; 27: 327-32.

47. Frizzera G, Peterson BA, Bayrd ED, et al. A systemic lymphoproliferative disorder with morphologic features of Castleman's disease: clinical findings and clinicopathologic correlations in 15 patients. J Clin Oncol 1985; 3: 1202-16.

48. Scott D, Cabral L, Harrington WJ Jr. Treatment of HIV-associated multicentric Castleman's disease with oral etoposide. Am J Hematol 2001; 66: 148-50.

49. van Rhee F, Stone K, Szmania S, et al. Castleman disease in the 21st century: an update on diagnosis, as sessment, and therapy. Clin Adv Hematol Oncol 2010; 8: 486-98

50. Sethi T, Joshi K, Sharma SC, et al. Radiation therapy in the management of giant lymph node hyperplasia. $\mathrm{Br}$ J Radiol 1990; 63: 648-50. 